\title{
Ocorrência Natural de Greeneria uvicola em Uva
}

\author{
Ludwig H. Pfenning ${ }^{1}$, Rita de Cássia S.Goussain ${ }^{2}$, Anderson R. Almeida ${ }^{1}$ \\ \& Eduardo Alves ${ }^{1}$
}

${ }^{1}$ Departamento de Fitopatologia, Universidade Federal de Lavras, Cx. Postal 3037, CEP 37200-000, Lavras, MG,
e-mail: ludwig@ufla.br; ${ }^{2}$ Centro de Ensino Superior de Rondonópolis, Coordenação de Agronomia,
CEP 78705-050, Rondonópolis, MT

(Aceito para publicação em 06/09/2005)

Autor para correspondência: Ludwig H. Pfenning

ABSTRACT

Natural occurrence of Greeneria uvicola in grape

Greeneria uvicola, the causal agent of bitter rot, is registered in a natural occurrence, and characterized and illustrated in Brazil for the first time.

Greeneria uvicola (Berk. \& M.A. Curtis) Punith. [sinônimo Melanconium fuligineum (Scribn. \& Viala) Cavara] é o agente causal da doença conhecida como "podridão amarga", uma das mais importantes doenças em bagas de uva (Vitis sp.). O fungo é conhecido somente na sua fase anamórfica, mas é atualmente agrupado junto aos Diaporthales com base em análises de seqüências do rDNA (Farr et al., Sydowia 53:185. 2001). Os sintomas iniciais típicos nas bagas se caracterizam por uma coloração acinzentada causada pelo crescimento do fungo formando os acérvulos na superfície dos frutos. Com a evolução da doença, os acérvulos adquirem uma cor mais escura e se rompem, liberando os conídios, o que leva a formação de uma massa preta (Figura 1 A-B). As bagas murcham e ficam mumificadas ainda no cacho. A doença pode ocorrer em todas as regiões produtoras de uva. Para Minas Gerais, há relato da ocorrência de G. uvicola na região de Andradas, como responsável por perda de até 50\% da safra (Abrahão et al., PAB 28:10. 1993). A ocorrência de G. uvicola foi observada em Lavras MG, Brasil, nos meses de dezembro a fevereiro dos anos 1999 a 2004, quando a maioria dos cachos apresentou os sintomas típicos da doença, não sendo observado nenhum tipo de sintoma nas folhas ou nos ramos. Das bagas infetadas foram preparadas lâminas para observação em microscópio ótico e eletrônico de varredura. Observaram-se os acérvulos na superficie do fruto rompendo a cutícula, a conidiogênese e conídios (Figura 1 D-E). Foi confirmada a conidiogênese do tipo enteroblástica fialídica (Figura F-G). As dimensões dos conídios variaram de 7,5 a $10,0 \mu \mathrm{m}$ de comprimento por 2,5 a $5,0 \mu \mathrm{m}$ de largura, em concordância com a descrição de Sutton e Gibson (CMI Descriptions, no. 535. 1977). Uma outra doença das bagas da uva, a "podridão da uva madura", causada por Colletotrichum gloeosporioides (Penz.) Penz. \& Sacc. (teleomorfo Glomerella cingulata (Stoneman) Spauld. \& H. Schrenk) é caracterizada pela produção de uma massa de conídios de cor alaranjada circundada por estruturas escuras. Em microscópio estereoscópio verifica-se a presença de setas pigmentadas, características para o gênero Colletotrichum (Figura 1C). Considerando a crescente importância da cultura da uva em diferentes regiões do país, a variabilidade patogênica de G. uvicola e a epidemiologia da doença devem ser estudadas e a distribuição monitorada. Trata-se da primeira descrição morfológica deste patógeno no Brasil.
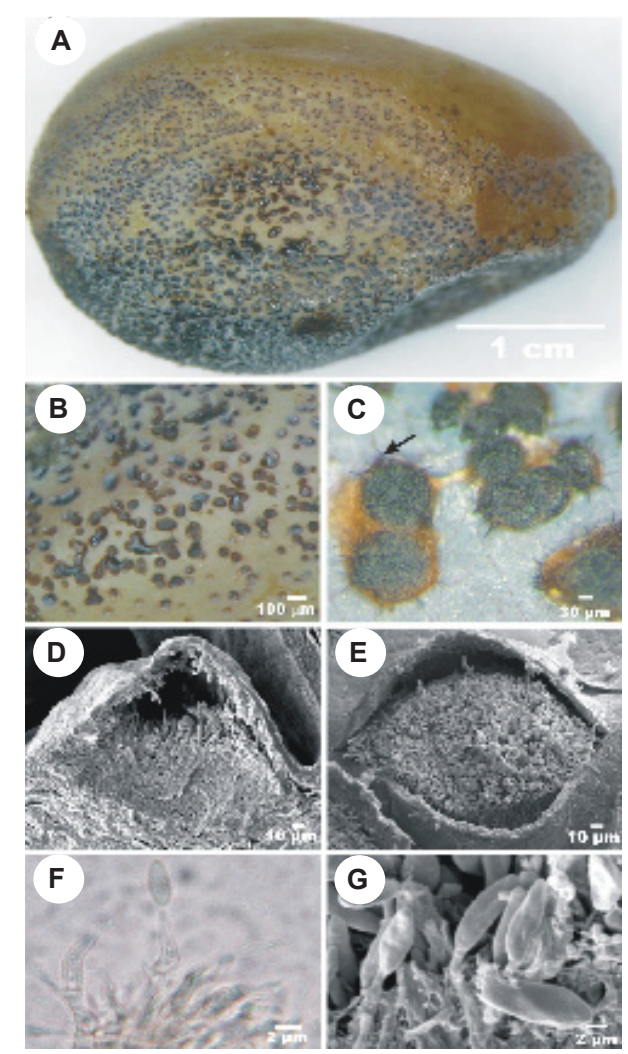

FIG. 1 - Greeneria uvicola. A, B. Sintoma no fruto da videira (Vitis sp.); D, E. acérvulos; F, G. Fiálides. Colletotrichum gloeosporioides; $\mathbf{C}$. acérvulo com setas. 